\title{
High connectivity of salmon farms revealed by aggregation, residence and repeated movements of wild fish among farms
}

\author{
Ingebrigt Uglem ${ }^{1, *}$, Tim Dempster ${ }^{2,3}$, Pål-Arne Bjørn ${ }^{4}$, Pablo Sanchez-Jerez ${ }^{5}$, \\ Finn Økland ${ }^{1}$ \\ ${ }^{1}$ Norwegian Institute of Nature Research, Tungasletta 2, 7485 Trondheim, Norway \\ ${ }^{2}$ SINTEF Fisheries and Aquaculture, 7465 Trondheim, Norway \\ ${ }^{3}$ Department of Zoology, University of Melbourne, Victoria 3010, Australia \\ ${ }^{4}$ NOFIMA, Muninbakken 9-13, PO Box 6122, 9291 Tromsø, Norway \\ ${ }^{5}$ Department of Marine Sciences and Applied Biology, University of Alicante, PO Box 99, 03080 Alicante, Spain
}

\begin{abstract}
Marine fish farms are widespread in coastal waters throughout the world, yet how they modify the movement patterns of wild fish species is largely unknown. We determined the spatiotemporal distribution of saithe Pollachius virens in a fjord system with intensive salmon cage aquaculture in Norway. Abundances of 8000 to 18000 saithe were estimated around 2 salmon farms in the fjord using an underwater video system. Residence of saithe around fish farms and movements among farms and throughout the fjord were studied using implanted acoustic transmitters and an extensive array of automatic receivers. Of the saithe equipped with acoustic tags, $63 \%$ were observed daily at one or more of the 3 farms in the fjord over a 3 mo period. When resident at a farm, saithe spent 8 to $10 \mathrm{~h} \mathrm{~d}^{-1}$ close to the sea-cages. Periods of residence at specific farms were interspersed with rapid and frequent movements to adjacent farms 1.6 to $4.7 \mathrm{~km}$ away. Of 24 tagged saithe, 15 moved among farms 2 to 21 times during the 3 mo period. If the movement patterns of the tagged fish are representative of the movements of untagged saithe, we estimate that fish from 2 different farms resulted in a total $( \pm$ SE) of $167112 \pm 41764$ and $7768 \pm 1831$ inter-farm movements during the 3 mo period. Thus, fish farms should be considered as connected, not only through ocean currents, but also through wild fish movements. If saithe share pathogens with farmed salmonids, their behaviours imply that they have the potential to act as vectors for diseases and parasites among salmon farms.
\end{abstract}

KEY WORDS: Aquaculture $\cdot$ Sea-cage $\cdot$ Aggregation $\cdot$ Movement $\cdot$ Pollachius virens $\cdot$ Tagging Tracking

\section{INTRODUCTION}

Coastal aquaculture is a large and expanding global industry. The farming of Atlantic salmon Salmo salar and rainbow trout Oncorhynchus mykiss in sea-cages occurs in Norway, Scotland, Canada and Chile, and produces over 1.5 million tons of fish each year (FAO 2008). In Norway, 1198 salmon and trout farms operated in 2007 and used a total of 1.16 million $t$ of fish feed to produce 689000 tons of fish (Norwegian Fish- eries Directorate 2008). In addition to salmonid farming, 98 further concessions produced other species such as cod, halibut and arctic char. Coastal fish farms now represent widespread structures in many coastal marine habitats.

Conventional management of the number of salmon farms in coastal waters relies largely on ecological knowledge of nutrient impacts (Carroll et al. 2003), the effects of escaped salmon (Soto et al. 2001, Thorstad et al. 2008), and the role salmon farms play in modifying 
sea lice infestations of wild salmonids (Bjørn et al. 2001, Krkosek et al. 2007). An additional impact involves the attraction and aggregation of large amounts of wild fish by salmon farms (e.g. Carss 1990, Dempster et al. 2009). The importance of this phenomenon for the management of wild fish populations and fish farming environments is gathering momentum (Dempster \& Sanchez-Jerez 2008).

Wild fish are resident near farms over a sufficient period to drive some physiological changes, such as modifying diets, fat content and tissue fatty-acid distributions (Skog et al. 2003, Fernandez-Jover et al. 2007). This may also increase levels of pollutants such as mercury in the tissues of long-term residents beneath farms (deBruyn et al. 2006). Biological evidence (increased liver somatic index) in farm-associated saithe Pollachius virens (Skog et al. 2003) and the results of tagging studies in southern Norway (Bjordal \& Skar 1992, Bjordal \& Johnstone 1993) suggest that saithe reside in the vicinity of specific farms for several months. Because of this, wild fish may also act as a source of pathogens to cultured fish in farms (e.g. Sepúlveda et al. 2004). However, little direct evidence exists to assess whether wild fish transmit pathogens among farms, in a similar way to the dispersal of bird flu by migrating wild birds (Chen et al. 2005).

Saithe are the most abundant wild fish observed at Norwegian salmon farms (Dempster et al. 2009). The life history of saithe in the NE Atlantic involves offshore spawning, an oceanic larval phase, recruitment to the coastal environment for a period of 2 to $4 \mathrm{yr}_{\text {, }}$ followed by offshore migration to spawning grounds (Nedreaas 1987, Armannsson et al. 2007). Tagging studies have shown that saithe remain within specific fjord areas during the coastal period (Sund 1922, Jakobsen 1978, Sarno et al. 1994), including fjords that contain salmon farms (Bjordal \& Johnstone 1993). Saithe typically occur in pelagic schools during the coastal period and range extensively within specific fjords (Armannsson et al. 2007). Diurnal movement patterns have been observed, with the highest activity and feeding levels occurring during daytime (Bjordal \& Johnstone 1993, Sarno et al. 1994).

In the present study, we sought to determine abundance at farms and the spatio-temporal movement patterns of saithe in a fjord with intensive salmon farming to evaluate the extent to which salmon farms are connected through inter-farm movements of saithe. We documented saithe aggregations at 2 full-scale salmon farms through the use of an underwater video system. To assess residence periods in the vicinity of salmon farms and movements among farms and within the fjord, we tracked saithe, using implanted acoustic transmitters and an extensive array of automatic receivers.

\section{MATERIALS AND METHODS}

Study site and salmon farm characteristics. Øksfjord is a fjord in northern Norway $\left(70.1^{\circ} \mathrm{N}, 22.2^{\circ} \mathrm{E}\right.$, Fig. 1). Three commercial Atlantic salmon farms (Steinviknes, Storviknes, Lille Skognes) were operating in the fjord from July to December 2006 when the study took place. Steinviknes and Lille Skognes each had 12 cages (25 $\mathrm{m}$ in diameter) containing Atlantic salmon $>1 \mathrm{~kg}$ in size (approximate total biomass for each farm was $2000 \mathrm{t}$ ) and were located at average water depths of 70 and $75 \mathrm{~m}$, respectively. Storviknes had 14 cages containing fish $<1 \mathrm{~kg}$ in size (approximate total biomass: $300 \mathrm{t}$ ) and was located at an average depth of $80 \mathrm{~m}$. Estimates of aggregations of wild fish using

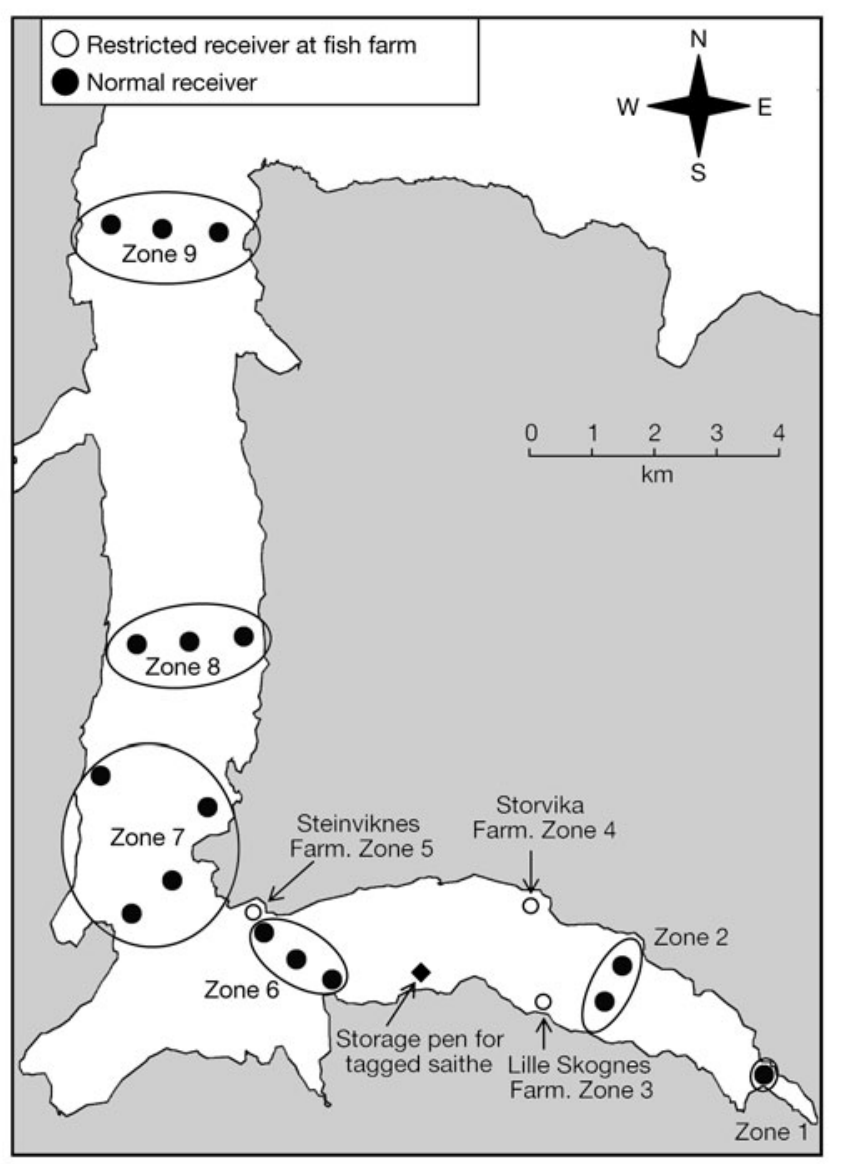

Fig. 1. Map of Øksfjord, northern Norway, and the locations of the 3 salmon Salmo salar farms and the receiver array used to track saithe tagged with acoustic transmitters. Twelve saithe Pollachius virens were tagged and released at each of the Steinviknes and Lille Skognes farms. @: Position of VR2 listening stations with a detection radius of $\sim 500 \mathrm{~m}$; O: the position of VR2 listening stations at fish farms with a restricted detection radius of $\sim 200 \mathrm{~m}_{i} \bullet$ : position of the holding pen and the location of tagging. Larger ovals encompass the specific detection zones (1 to 9) in the fjord 
video-based counts were carried out at Steinviknes and Lille Skognes, and saithe Pollachius virens tagged with acoustic transmitters were released at both of these farms. Automatic receivers were positioned at all 3 fish farms and also at other locations in the fjord system ( $\mathrm{n}=19$ loggers; Fig. 1). Distances from the Steinviknes farm to the Storviknes and Lille Skognes farms were 4.5 and $4.7 \mathrm{~km}$, respectively, while the distance between Storviknes and Lille Skognes was $1.6 \mathrm{~km}$ (Fig. 1).

Estimation of saithe abundances and sizes around farms. Saithe abundances were estimated through video counts at various depths at the Steinviknes and Lille Skognes farms (Fig. 1). The video camera-rig consisted of a black and white $1 / 3$ ' Sony EXview HAD CCD camera contained within a half-spherical housing and $4 \times 2 \mathrm{~W}$ monochromatic amber LED lights mounted above the camera to provide even, dispersed lighting. The camera was controlled from the surface by a single $9 \mathrm{~mm}$ polyurethane/Kevlar cable, and recordings were made on a Sony mini-DV recorder.

We used stationary timed counts with the camera within the housing slowly revolving through $360^{\circ}$. For each count, a 1 min recording was made which consisted of 2 complete revolutions (30 s) of the camera in $360^{\circ}$. In the water column, fish were counted in a cylindrical volume that varied with depth due to varying visibilities. Count volumes within which fish were identifiable varied from $\sim 387 \mathrm{~m}^{3}$ at depths $>80 \mathrm{~m} \mathrm{(4 \textrm {m }}$ height $\times 5 \mathrm{~m}$ radius from the camera), to $\sim 707 \mathrm{~m}^{3}$ at depths of $<80 \mathrm{~m}(4 \mathrm{~m}$ height $\times 7.5 \mathrm{~m}$ radius from the camera), based on preliminary work with objects at known distances. All count volumes accounted for camera blind spots. Bottom counts included the water column to $1 \mathrm{~m}$ above the substratum, with volumes

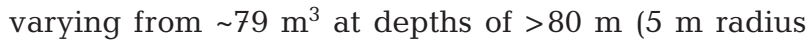
from the camera), and $\sim 177 \mathrm{~m}^{3}$ at depths $<80 \mathrm{~m}(7.5 \mathrm{~m}$ radius from the camera). All data were standardised to $500 \mathrm{~m}^{3}$. For each $1 \mathrm{~min}$ recording, saithe were counted separately for the two $30 \mathrm{~s}$ revolutions of the camera. The maximum abundance in either of the 2 revolutions was used, as is typical in baited remote underwater video (BRUV) studies (e.g. Heagney et al. 2007). A full description of the technique and its method-specific biases and limitations are given in Dempster et al. (2009).

At each farm, fish were counted on 3 random days within a period of $1 \mathrm{wk}$ in July 2006 around the release date (July 13) of the tagged saithe. Three replicate camera drops were made 1 to $5 \mathrm{~m}$ from the cage edge on each day between 09:00 and 17:00 $\mathrm{h}$, and video recordings were made at 5, 10, 20, 40 and $60 \mathrm{~m}$ and the bottom. Feeding at the 2 salmon farms during July occurred continuously from 06:00 to 20:00 h. Video counts were scaled-up to estimate the total abundance at each farm, following the method of Dempster et al. (2009). The attractive volume of each farm to wild fish was defined as the area enclosed by the cages plus $5 \mathrm{~m}$ around the cages multiplied by the average farm depth. The volume occupied by cages containing salmon was subtracted from the available volume. Both Steinviknes and Lille Skognes had an attractive farm area of $7500 \mathrm{~m}^{2}$. The mean abundance per $500 \mathrm{~m}^{3}$ over the 3 sampling times at each farm for each depth stratum was multiplied by the total number of $500 \mathrm{~m}^{3}$ counts possible in each specific depth stratum. The scaled-up estimates from the different depth strata were combined to give the total number of saithe at a farm.

To estimate the size structure of saithe aggregated at each farm, 50 and 55 fish were captured throughout the entire water column using fishing rods and lures (red plastic worms) with barbless hooks (size 1/0) at Steinviknes and Lille Skognes farms, respectively, on the same day (July 6) as fish were captured for tagging. These fish were measured (total length, TL) and weighed.

Tagging and tracking of saithe. Residence at farms and movements among farms and in the fjord system were studied by tagging 24 saithe with acoustic transmitters and by monitoring their spatio-temporal distribution using an array of passive listening stations positioned throughout Øksfjord (Fig. 1). The saithe were caught around Lille Skognes farm at shallow depths ( 1 to $10 \mathrm{~m}$ ) to avoid barotrauma during capture. Fishing rods with lures (red plastic worms) fitted with a single barbless hook (size 1/0) were used to capture the saithe. After capture, the saithe were transferred to a small flat-bottom storage pen (circumference: $20 \mathrm{~m}$, depth: $5 \mathrm{~m}$ ) positioned at an approximately similar distance to each of the 2 farms where the fish were later released (Fig. 1). The saithe were kept at this location for $7 \mathrm{~d}$ to reduce capture and tagging stress, as well as possible site fidelity to the capture location. The saithe were captured on July 6, tagged on July 10 and then released on July 13, either at Lille Skognes farm or at Steinviknes farm (Table 1). Five of the 12 saithe released at each of the farms were tagged with transmitters equipped with a pressure sensor, which allowed the swimming depth of these fish to be measured. Depth data were only used to determine if mortality of an individual had occurred during long, continuous periods of detection by the same receiver.

Immediately before tagging, the saithe were collected from the storage pen using a hand net. The fish were then anaesthetised by immersion in an aqueous solution of 2-phenoxy-ethanol (Sigma Chemicals; $0.3 \mathrm{ml} \mathrm{l}^{-1}$, immersion period: $3 \pm 1 \mathrm{~min}$, temperature in solution: $13.5^{\circ} \mathrm{C}$ ) and placed ventral side up onto a $\mathrm{V}$ shaped surgical table. An incision $(\sim 1.5 \mathrm{~cm})$ was made 
Table 1. Pollachius virens. Length and weight of fish released and sampled at the Steinviknes and Lille Skognes farms. R: released; S: sampled

\begin{tabular}{|c|c|c|c|c|c|c|c|c|}
\hline \multirow[t]{2}{*}{ Farm location } & \multirow[t]{2}{*}{$\mathrm{R} / \mathrm{S}$} & \multirow[t]{2}{*}{$\mathrm{n}$} & \multicolumn{3}{|c|}{ Fork length $(\mathrm{cm})$} & \multicolumn{3}{|c|}{ Weight $(\mathrm{kg})$} \\
\hline & & & Mean \pm SE & Max. & Min. & Mean $\pm \mathrm{SE}$ & Max. & Min. \\
\hline \multirow[t]{2}{*}{ Steinviknes } & $\mathrm{R}$ & 12 & $48.7 \pm 1.2$ & 60.5 & 44.1 & $1.1 \pm 0.11$ & 2.2 & 0.8 \\
\hline & S & 50 & $45.3 \pm 0.7$ & 63.0 & 39.0 & $1.0 \pm 0.06$ & 2.2 & 0.6 \\
\hline \multirow[t]{2}{*}{ Lille Skognes } & $\mathrm{R}$ & 12 & $47.5 \pm 1.7$ & 60.8 & 42.5 & $1.0 \pm 0.14$ & 2.3 & 0.6 \\
\hline & $\mathrm{S}$ & 55 & $47.0 \pm 0.7$ & 63.0 & 38.0 & $1.1 \pm 0.06$ & 2.5 & 0.6 \\
\hline
\end{tabular}

on the ventral surface posterior to the pelvic girdle using a scalpel. A transmitter (VEMCO, Model V131H-R256 or V13-Pressure-1H-S256; $13 \times 35$ or $44 \mathrm{~mm}$; weight in water: 6 or $6.6 \mathrm{~g}$; frequency: $69 \mathrm{kHz}$; ratio transmitter mass in water to fish mass: 0.3 to $1.1 \%$ ) was inserted through the incision and pushed into the body cavity above the pelvic girdle. The incision was closed using 2 independent silk sutures (3/0 Ethicon). The fish, including the gills, were regularly sprayed with water during the surgery. Surgery time was 2:21 \pm 0:45 min (mean $\pm \mathrm{SD}$ ). After surgery, the fish were allowed to recover for $3 \mathrm{~d}$ in the storage pens before they were transported to the release farms (Fig. 1). Immediately prior to transport, the tagged fish were transferred to a tank (volume: 800 l) with circulating water onboard a boat. The transportation time to the release sites was <30 min. All tagged fish showed normal swimming behaviour immediately after release. Handling and tagging was conducted according to the Norwegian regulations for the treatment and welfare of animals.

The movements and distribution of the tagged saithe were recorded by 19 automatic receivers (Vemco Model VR2) positioned either across the fjord or individually to monitor fish farms (Fig. 1). The receivers were deployed on anchored ropes at sites between 23 and $300 \mathrm{~m}$ water depth. Receivers in the fjord were attached to the ropes at approximately half the distance to the bottom, while receivers at farms were suspended in the middle of the farm $20 \mathrm{~m}$ below the water surface. The distance between receivers positioned across the fjord was 500 to $800 \mathrm{~m}$. The detection range of the receivers located at farms was restricted to estimate the presence of tagged saithe in the immediate vicinity by attaching a waterproof conical plastic cap filled with air over the hydrophone (Uglem et al. 2008). Range tests showed that the average detection range of the unrestricted receivers was defined by a radius of 600 to $700 \mathrm{~m}$, while the range of the restricted receivers at the fish farms varied from 150 to $200 \mathrm{~m}$ in radius. The transmitters emitted unique coded signals such that each fish could be individually recognised. When a tagged saithe was present within a receiver range, the transmitter identification code, date and time of detection, and depth for the 10 fish with depth tags were recorded. All receivers were deployed for 12 wk from July 13, except for the receiver at Lille Skognes farm, which was deployed for $28 \mathrm{wk}$ to record longer term residence at this farm.

Analyses of telemetry data. The receiver array was organised into 9 zones which consisted of between 1 to 4 receivers (Fig. 1). Detection of a fish at one or more of the receivers within the different zones was defined as presence within that zone. To exclude false signals, single detections within a $30 \mathrm{~min}$ period were considered erroneous. Presence at a farm or within a zone was thus defined as when a fish was detected twice or more within a 30 min period. Likewise, a fish was considered as having left a farm or a zone if the period between detections was $>30$ min. Movements among farms were defined as 1-way movements; if a fish moved from one farm to another and then returned, this was recorded as 2 separate movements. Movement speeds among farms $\left(\mathrm{km} \mathrm{h}^{-1}\right)$ were estimated as the shortest distance between the 2 farms divided by the time from the last detection at the first farm until the first detection at the second farm. Diurnal variation in the presence of saithe at Steinviknes and Lille Skognes farms was examined by comparing the proportions of the total number of fish observed during the day from Days 9 to 50. This period was selected as the proportions of fish observed at the farms were relatively high and stable. The days were divided into 6 periods, each of $4 \mathrm{~h}$ duration, starting at 01:00 h. Data from the first $8 \mathrm{~d}$ were removed from this analysis to avoid the influence of possible post-tagging effects.

Statistical analyses. To test whether abundances varied among depths at each farm, we used a 1-way ANOVA. Prior to ANOVA, heterogeneity of variance was tested with Cochran's $C$-test. Data were $\ln (x+1)$ transformed if variances were significantly different at $p=0.05$. As ANOVA is robust to heterogeneity of variances (Underwood 1997), ANOVAs were performed and the level of significance set at 0.01 when variances remained heterogeneous even after transformation. Generalised linear model (GLM) univariate analyses were used to test for differences in the residence periods among time of the day (6 periods of $4 \mathrm{~h}$, fixed fac- 
tor) and date (week, covariate) after initiation of the study at both the Steinviknes and Lille Skognes farms. Fisher exact tests were used to determine whether the number of fish moving among farms differed between release farms.

\section{RESULTS}

\section{Saithe abundances and size structures at Steinviknes and Lille Skognes}

Video-based estimates indicated that saithe were abundant at both Steinviknes and Lille Skognes farms (Fig. 2) during the week when the tagged saithe were released. At Lille Skognes, saithe were significantly more abundant in the upper part of the water column (5, 10 and $20 \mathrm{~m}$ counts) than deeper beneath the farm $(40,60 \mathrm{~m}$ and bottom counts; $F=3.4, \mathrm{p}=0.04)$. At Steinviknes, saithe were more evenly distributed across all depth strata sampled $(F=0.54, \mathrm{p}=0.7)$. Camera-based estimates indicated that a total of (mean \pm SE) $18067 \pm 4515$ and $7768 \pm 1831$ saithe were aggregated within the immediate attractive areas of Steinviknes and Lille Skognes, respectively. Size distributions of saithe captured at Steinviknes (Table 1) indicated that the 24 saithe used for tagging were representative of the fish aggregated in the immediate vicinity of farms.

\section{General patterns of saithe movement in Øksfjord}

Tagged saithe were detected in all 9 zones throughout the Øksfjord system during the 3 mo study period

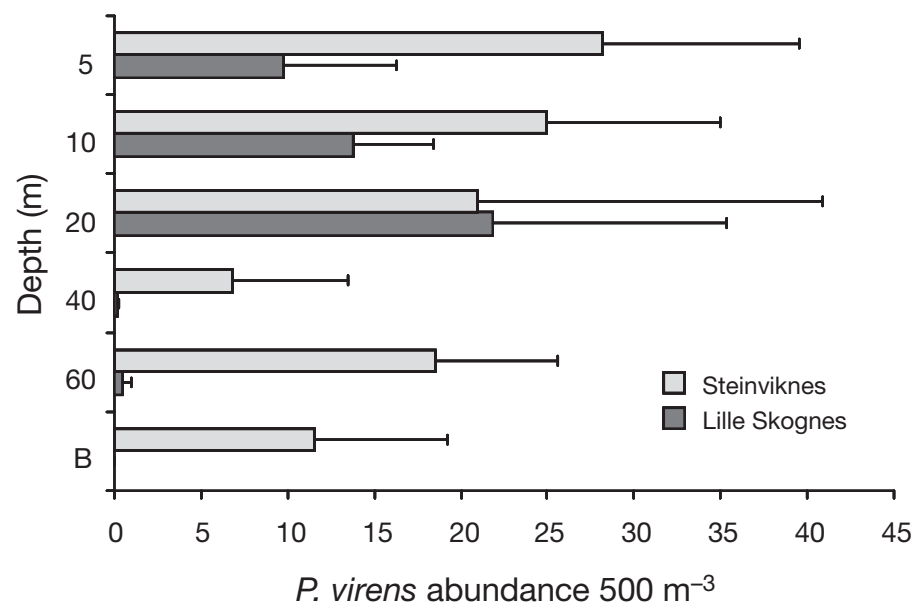

Fig. 2. Pollachius virens. Abundances of wild saithe $500 \mathrm{~m}^{-3}$ by depth strata around the Steinviknes and Lille Skognes farms in Øksfjord in July 2006. Each bar gives the mean $( \pm \mathrm{SE})$ of 9 video counts. B: bottom count

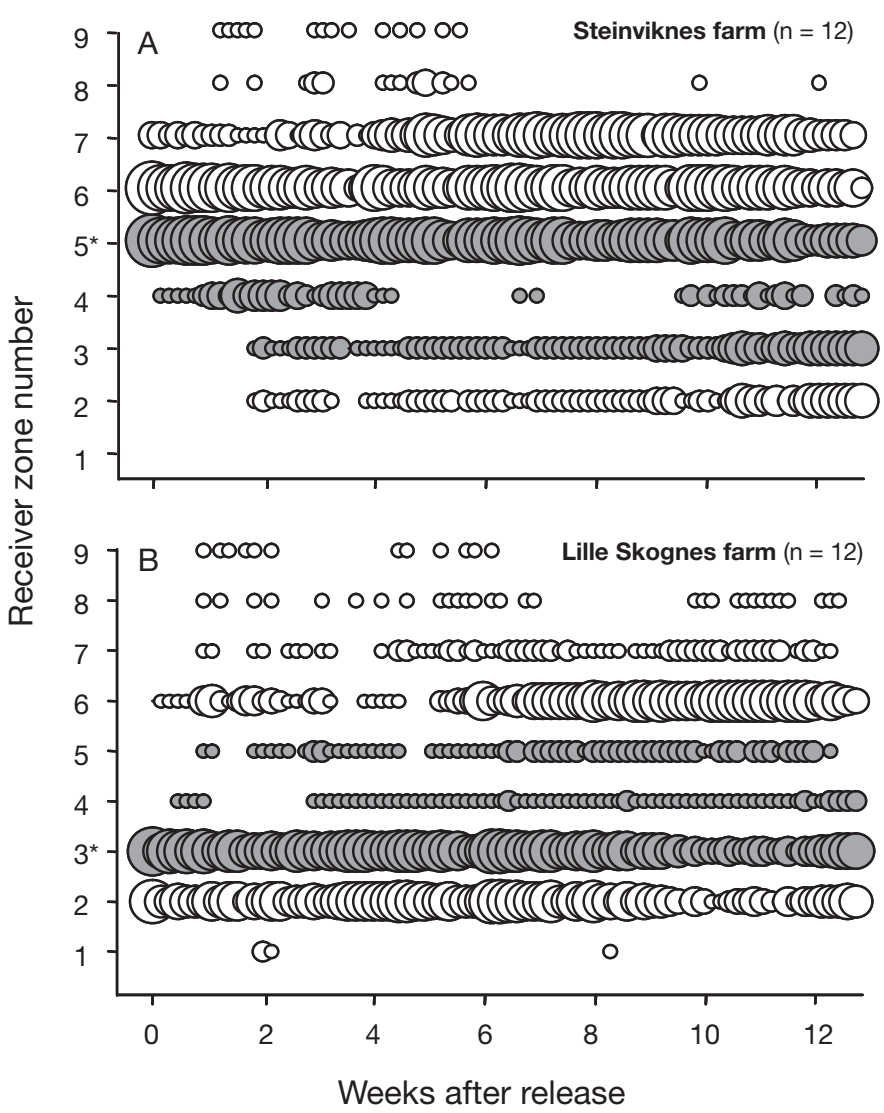

Fig. 3. Pollachius virens. Proportion of tagged saithe (given by bubble size: the smallest bubble represents $8 \%$ or 1 fish, while the largest represents $100 \%$ or 12 fish) recorded by the receivers in Detection Zones 1 to 9 (see Fig. 1 for locations) of the fish tagged with acoustic tags released at: (A) Steinviknes farm and (B) Lille Skognes farm each day for the $90 \mathrm{~d}$ following release. Bubbles shaded in grey denote the salmon farms, and zones marked with an asterisk on the $y$-axis indicate the farms where the saithe were originally released

(Fig. 3), indicating that saithe periodically moved away from the release farm to natural areas of the fjord system. Six of 24 tagged saithe visited the outer part of the fjord (Zone 9), but only 2 of these fish were never observed again in other zones of the fjord. These 2 fish ( 1 from each of the 2 release groups) were thus considered as having migrated out of the fjord, while all other fish remained within the receiver array during the study period. In general, saithe were predominantly detected around the farm of release and in the areas close to the farm (Steinviknes: Zones 6 and 7; Lille Skognes: Zone 2; Fig. 3). However, 9 of 12 saithe released at Lille Skognes made repeated along-shore movements and were detected in Zone 6 during Weeks 6 to 12 and were recurrently detected by the 2 southernmost receivers in this zone, without being detected at the Steinviknes farm (Zone 5). 


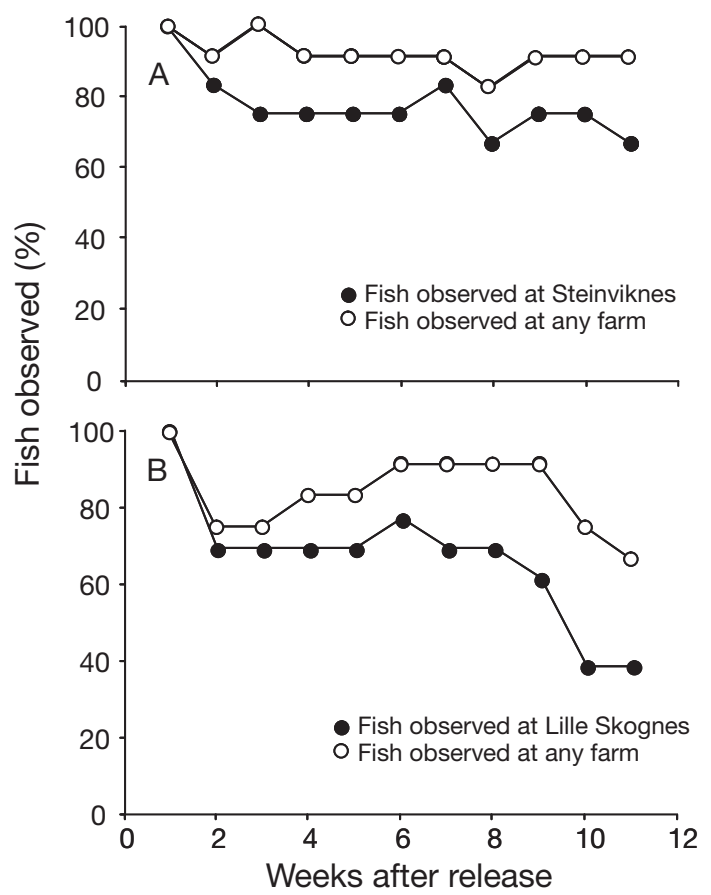

Fig. 4. Pollachius virens. Proportion of tagged saithe released at: (A) the Steinviknes farm $(\mathrm{n}=12)$ and $(\mathrm{B})$ the Lille Skognes farm $(n=12)$, observed within each week at the release farm

(๑) or at any of the 3 farms in Øksfjord (O)

\section{Residence at farms}

During the first $11 \mathrm{wk}$ after release, 67 to $83 \%$ of the saithe released at Steinviknes farm were regularly observed around the release farm (Fig. 4A). For the first $8 \mathrm{wk}$ after release, 63 to $75 \%$ of the saithe released at Lille Skognes were regularly observed around the release farm, while the proportion of tagged fish observed dropped to $42 \%$ during Week 11 (Fig. 4B). Thereafter, the proportion of fish released at Lille Skognes and observed at the release farm increased again to $70 \%$ between Week 12 and 16, before it stabilised at around 25 to $33 \%$ between Week 16 and 28 (data not shown). Residence at any of the 3 farms in Øksfjord was markedly higher than residence at the release farms alone. When fish observed at all 3 farms

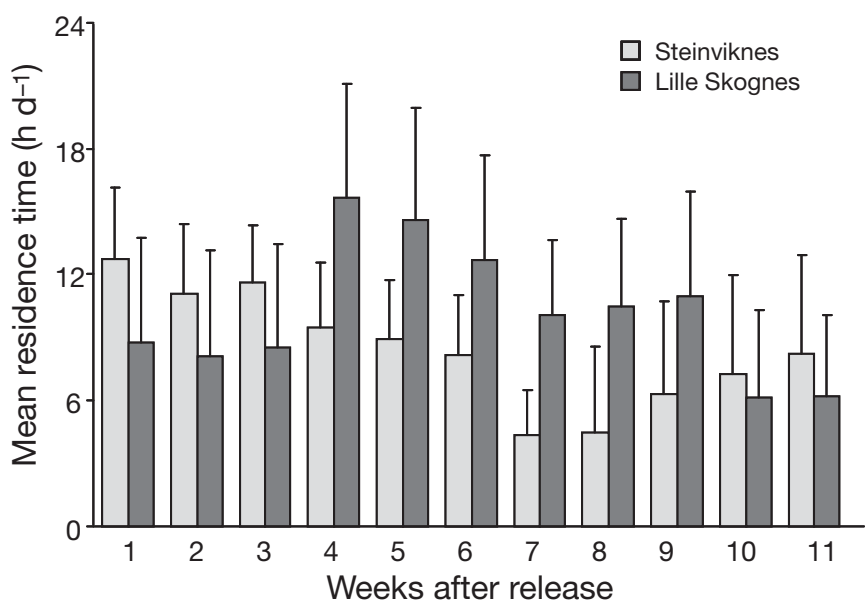

Fig. 5. Pollachius virens. Residence periods per day (mean \pm $2 \mathrm{SE}$ ) at any of the 3 salmon farms in Øksfjord in relation to weeks after initiation of the study. Fish released at Steinviknes and Lille Skognes farms are indicated with white and grey bars, respectively

in the fjord were taken into account, the proportion of released fish regularly observed at any farm during the first $12 \mathrm{wk}$ of the study varied between 67 and $100 \%$, with an average of $88 \%$ (Fig. 4 ).

The residence period at any of the 3 farms in the fjord system for saithe released at the Steinviknes farm varied significantly among the study weeks $(F=2.25$, $\mathrm{p}=0.02$; Fig. 5). The daily residence period at any farm decreased from $12.7 \mathrm{~h} \mathrm{~d}^{-1}$ the first week post-release to $4.3 \mathrm{~h} \mathrm{~d}^{-1} 7 \mathrm{wk}$ post-release. From Week 7 to 12 , the residence period at a farm stabilised and varied between 4.5 and $7.7 \mathrm{~h} \mathrm{~d}^{-1}$ for the Steinviknes saithe. For saithe released at the Lille Skognes farm, there was no significant variation in residence periods per day at any of the 3 farms related to the weeks after release $(F=1.72$, $\mathrm{p}=0.08$; Fig. 5). On average, fish released at Steinviknes and Lille Skognes stayed at a farm 8.4 and $10.0 \mathrm{~h}$ $\mathrm{d}^{-1}$, respectively.

Residence at the release farm varied significantly with the time of day (Table 2) both for the fish released at Steinviknes (period: $F=53.9, \mathrm{p}<0.001$ ) and at Lille Skognes (period: $F=11.4, \mathrm{p}<0.001$ ). The abundance of tagged saithe at the farms was highest during the

Table 2. Pollachius virens. Mean proportions of the maximum number of tagged fish observed at the release farms during the day in relation to the time of the day. Each day is divided into 6 periods, and data from $42 \mathrm{~d}$ (Days 9 to 50) are presented. Values are means $\pm \mathrm{SE}$

\begin{tabular}{|c|c|c|c|c|c|c|}
\hline \multirow[t]{2}{*}{ Farm } & \multicolumn{6}{|c|}{-Time of dav (h) } \\
\hline & $01: 00-04: 00$ & $05: 00-08: 00$ & 09:00-12:00 & $13: 00-16: 00$ & $17: 00-20: 00$ & $21: 00-24: 00$ \\
\hline Steinviknes & $45 \pm 3.5$ & $96 \pm 1.4$ & $93 \pm 1.9$ & $80 \pm 3.3$ & $66 \pm 3.8$ & $44 \pm 4.4$ \\
\hline Lille Skognes & $78 \pm 3.8$ & $92 \pm 1.7$ & $89 \pm 2.3$ & $87 \pm 2.4$ & $78 \pm 3.0$ & $65 \pm 3.8$ \\
\hline
\end{tabular}


early morning hours, which coincided with the beginning of feeding of salmon at the farms (Table 2). Thereafter, abundance decreased throughout the day. The diurnal residence pattern also varied significantly depending on the week of observation (Steinviknes, week: $F=13.9, \mathrm{p}<0.001$; Lille Skognes, week: $F=6.6$, $\mathrm{p}=0.01$ ). Diurnal variation in abundance at the Steinviknes farm throughout the study was relatively unsystematic, while differences in the abundance of tagged fish at the Lille Skognes farm were greater during the day than at night towards the end of the observation period.

\section{Among-farm movements}

Fifteen of the 24 tagged fish (63\%) moved from the release farm to 1 or both of the adjacent farms in the fjord system. On average, these 15 saithe made 8 interfarm movements (range: 2 to 21) during the 3 mo study period (Table 3 ). Movement speeds among farms varied from 0.53 to $3.38 \mathrm{~km} \mathrm{~h}^{-1}$, with a mean movement speed of $1.7 \mathrm{~km} \mathrm{~h}^{-1}$. All $12(100 \%)$ fish released at Steinviknes farm first visited the Storvika farm. Six (50\%) of the Steinviknes fish visited the Storvika farm only, while the other $6(50 \%)$ were observed at both the Storviknes and Lille Skognes farms. Little evidence existed that fish released at Steinviknes showed specific homing behaviour to their capture location at Lille Skognes, as no movement to the Lille Skognes farm

Table 3. Pollachius virens. Overview of movement patterns of the 15 fish that moved from the release farm to 1 or more of the other salmon farms. S: Steinviknes; ST: Storvika; LS: Lille Skognes

\begin{tabular}{|lccl|}
\hline $\begin{array}{l}\text { Release } \\
\text { farm }\end{array}$ & $\begin{array}{c}\text { No. of } \\
\text { movements }\end{array}$ & $\begin{array}{c}\text { 1st movement } \\
\text { (Day) }\end{array}$ & Sequence of farm visits \\
\hline $\mathrm{S}$ & 2 & 15 & ST-S \\
$\mathrm{S}$ & 2 & 68 & ST-LS \\
$\mathrm{S}$ & 4 & 13 & ST-LS-ST-LS \\
$\mathrm{S}$ & 4 & 22 & ST-S-ST-S \\
$\mathrm{S}$ & 4 & 81 & ST-S-ST-S \\
$\mathrm{S}$ & 7 & 66 & ST-S-ST-LS-ST-S-ST \\
$\mathrm{S}$ & 8 & 12 & ST-LS-ST-LS-ST-S-ST-LS \\
$\mathrm{S}$ & 11 & 8 & ST-S-ST-S-ST-S-ST-S-ST-S-ST \\
$\mathrm{S}$ & 12 & 8 & ST-S-ST-S-ST-S-ST-S-ST-S-ST-S \\
$\mathrm{S}$ & 16 & 66 & ST-S-ST-S-ST-LS-ST-S-ST-S-ST- \\
& & & S-ST-S-ST-LS \\
$\mathrm{S}$ & 20 & 8 & ST-S-ST-S-ST-S-ST-S-ST-S-ST-S- \\
& & & ST-S-ST-S-ST-S-ST-S \\
$\mathrm{S}$ & 21 & 1 & ST-S-ST-S-LS-ST-LS-ST-S-ST-S- \\
& & & ST-S-ST-S-ST-S-ST-S-ST-LS \\
LS & 2 & 43 & ST-S \\
LS & 5 & 4 & ST-S-ST-LS-ST \\
LS & 5 & 20 & ST-S-ST-S-ST \\
\hline
\end{tabular}

occurred for the first $14 \mathrm{~d}$ by any fish released at Steinviknes. Three of $12(25 \%)$ tagged saithe released at Lille Skognes visited both the Steinviknes and Storvika farms. The number of fish moving to other farms was higher for fish released at the Steinviknes farm compared to the Lille Skognes farm (Fisher exact test, $\mathrm{p}<$ 0.001). This was despite Steinviknes being the most isolated farm in the fjord, with straight line distances of 4.5 and $4.7 \mathrm{~km}$ to Storviknes and Lille Skognes, respectively. The average daily period of residence at a farm other than the release farm for the 15 saithe that moved among farms was $5.0 \mathrm{~h}$ (range: 0.1 to $19.1 \mathrm{~h}$ ), indicating that, while some fish remained only briefly, others re-aggregated at the second farm.

\section{DISCUSSION}

The general movement patterns of the tagged saithe in the Øksfjord system concur with previous observations on coastal movements and behaviour of saithe of similar size and age (Sund 1922, Jakobsen 1978, Nedreaas 1987, Sarno et al. 1994, Armannsson et al. 2007). The tagged saithe largely remained within the Øksfjord system, with only 2 fish leaving the fjord during the 3 mo study period. While resident in the fjord, the tagged fish ranged extensively over 10 s of kilometres. Large numbers of saithe aggregated close to the cages at salmon farms in Øksfjord, and tagged saithe were resident in the immediate vicinity of the same farms for prolonged periods (days to months). This aggregative behaviour and residence is likely related to the high availability of waste feed originating from salmon farms. Saithe are pelagic feeders (Bogetveit et al. 2008) and when caught in association with salmon farms, they are typically found to contain lost pellets, which have fallen from the cage through the water column (Skog et al. 2003). Moreover, the diurnal pattern in the residence of saithe around fish farms observed in the present study, which broadly correlated with farm feeding times, provides further evidence that lost feed is a likely cause of aggregation.

A high proportion of the tagged saithe moved frequently and repeatedly from the release farm to 1 or 2 other farms. Inter-farm movements varied both among individuals and among the groups of fish released at the Steinviknes and Lille Skognes farms. The difference in inter-farm 
movements between the 2 release locations may have been due to the fact that all tagged fish were captured at the Lille Skognes farm and thus showed lower fidelity to the Steinviknes farm. However, the movement patterns of the Steinviknes fish did not resemble typical homing behaviour to the Lille Skognes capture site. Fish released at the Steinviknes farm tended to be more frequently resident at this farm over time compared to the fish released at the Lille Skognes farm. Further, the behavioural patterns of the Steinviknes fish were characterised by frequent movements to the Storvika farm, which was located on the same side of the fjord. Similarly, a high proportion of the fish released at the Lille Skognes farm moved repeatedly to an area located on the same side of the fjord as this farm. Thus, the more frequent inter-farm movements of the Steinviknes fish compared to the Lille Skognes fish could be related to a general behavioural pattern characterised by along-shore movements, rather than an artefact of being released at a different location than the capture location. Our study provides little information as to why residence periods at farms varied among fish or why fish left the vicinity of farms. However, previous work on the behaviour of pelagic fish aggregated around artificial structures suggests that food availability is a primary driver of the duration of association (Dagorn et al. 2000).

Minimum inter-farm movement speeds of tagged saithe were calculated based on the time elapsed between the last observation at 1 farm and the first observation at the second farm, and varied from 0.53 to $3.38 \mathrm{~km} \mathrm{~h}^{-1}$. The fastest speed corresponds to net swimming speeds of $<2$ body lengths $\mathrm{s}^{-1}$. As saithe are capable of sustained swim speeds of up to 3.4 body lengths $\mathrm{s}^{-1}$ (He \& Wardle 1988), the minimum interfarm movement speed estimates fall well within the possible range.

The aggregation of saithe around salmon farms is a widespread phenomenon, with schools of 2000 to 40000 saithe documented at 9 salmon farms across the latitudinal range of 59 to $70^{\circ} \mathrm{N}$ throughout coastal Norway (Dempster et al. 2009). In Øksfjord, the tagged saithe moved a total of 123 times among farms within the 3 mo tracking period. If the $18067 \pm 4515$ and $7768 \pm 1831$ (SE) saithe, which were estimated to aggregate at the Steinviknes and Lille Skognes farms, respectively, moved similarly to the tagged fish at each farm (Steinviknes: 111 movements by 12 fish in 3 mo; Lille Skognes: 12 movements by 3 fish in $3 \mathrm{mo}$ ), we estimate that $167112 \pm 41764$ (SE) among farm movements were made by fish from Steinviknes and $7768 \pm 1831$ (SE) by fish from Lille Skognes during the 3 mo study.

We have documented that salmon farms are connected not only through ocean currents (e.g. Bjørn et al. 2003, Chambers \& Ernst 2005), but also through wild fish movements. In Øksfjord, tagged saithe resided at salmon farms for prolonged periods, interspersed with rapid and frequent movements to adjacent farms and movements throughout the fjord system to non-farming locations. The movement patterns of saithe in fjord systems with salmon farming might predispose them to act as vectors of disease among farms and among adjacent wild populations of fish.

For wild fish to act as vectors of diseases among salmon farms or to adjacent wild fish populations, they must share diseases with farmed salmonids. A range of viruses, diseases and parasites may be shared by salmonids, saithe and other gadoids, including the salmonid alphavirus (Graham et al. 2006), the infectious pancreatic necrosis virus (Wallace et al. 2008), the ectoparasitic copepod Caligus elongatus (Øines et al. 2006), the Vibrio anguillarum bacteria (Hastein \& Smith 1977) and approximately 20 other pathogens (Bricknell et al. 2006). It is possible that wild fish also act as symptom-free carriers of certain pathogens. However, whether salmon can infect saithe resident in the near vicinity of sea-cages and vice versa is unknown for the majority of shared diseases. Our observations of abundances of saithe in the upper part of the water column and their close physical proximity just metres distant from the farmed salmon raises the possibility of transfer of various pathogens through a water-borne route or through faeces from salmon that drift out of the cages and faeces from saithe that drift into the cages. Further research, possibly through challenge experiments (e.g. Christie et al. 2007), is required to verify if and to what extent shared diseases are transferred between saithe and farmed salmon under realistic conditions.

The localisation of salmon farms in Norway is partly based on minimum allowed distances among farms as a precautionary measure to avoid the spread of disease and to ensure dispersal of nutrients through water currents (Ervik et al. 1997, Hansen et al. 2001, Stigebrandt et al. 2004). Our results add a new component to this framework. If wild fish are serious vectors of salmon farm diseases, this implies that the existing spacing system for fish farms requires reconsideration based on knowledge of movements of wild fish in fjord and coastal waters. While saithe are the most abundant wild fish aggregated around Norwegian salmon farms, Dempster et al. (2009) identified Gadus morhua, Melanogrammus aeglefinus and Scombrus scombrus as additional potential candidates acting as vectors, based on their propensity to aggregate at farms. Moreover, our observation that $100 \%$ of the tagged saithe released at Steinviknes moved to other farms despite it being the most distant farm from other farms in the fjord, while only $25 \%$ of the saithe released at Lille 
Skognes migrated to other farms, leads to the hypothesis that the location of some farms may enhance their potential to facilitate disease transfer by wild fish. A larger-scale study of the connectivity of salmon farms in a region with numerous farms at distances from one another is required to test this hypothesis.

\section{Conclusions}

Numerous wild saithe resided around salmon farms in a typical Norwegian farm area, and a high proportion of these fish made rapid and repeated movements among farms. Salmon farming locations separated on a scale of kilometres are therefore highly connected through the ecosystem process of wild fish aggregation and residence at salmon farms followed by subsequent movements to adjacent farms. Connectivity of fish farms through wild fish movements might have significant ramifications for the horizontal spread of pathogens. As fish farming intensifies in coastal regions throughout the world, knowledge of the connectivity of farm locations through wild fish movements may prove critical to minimise disease outbreaks in both fish farms and adjacent wild fish populations.

Acknowledgements. We thank the staff at the fish farms in Øksfjord (Volden group/Grieg Seafood ASA) for their help during the course of the study. In addition, we thank Tom Andersen and Rune Nilsen for assistance during the fieldwork and Eva Thorstad for constructive comments on the manuscript. This research was funded by the Norwegian Research Council through the strategic research project (AS31649) and through the CoastACE project (No. 173384).

\section{LITERATURE CITED}

Armannsson H, Jonsson ST, Neilson JD, Marteinsdottir G (2007) Distribution and migration of saithe (Pollachius virens) around Iceland inferred from mark-recapture studies. ICES J Mar Sci 64:1006-1016

Bjordal A, Johnstone ADF (1993) Local movements of saithe (Pollachius virens L.) in the vicinity of fish farm cages. ICES Mar Sci Symp 196:143-146

Bjordal Å, Skar AB (1992) Tagging of saithe (Pollachius virens L.) at a Norwegian fish farm: preliminary results on migration. ICES C M 1992/G:35. ICES, Copenhagen

Bjørn PA, Finstad B, Kristoffersen R (2001) Salmon lice infection of wild sea trout and Arctic char in marine and freshwaters: the effects of salmon farms. Aquac Res 32:947-962

Bjørn PA, Dale T, Koren C, Slagstad D, Finstad B (2003) Risk for and measures against salmon lice infection on wild and farmed salmonids. Fiskeriforskning Report 21:1-27

Bogetveit FR, Slotte A, Johannessen A (2008) The ability of gadoids to take advantage of a short-term high availability of forage fish: the example of spawning aggregations in Barents Sea capelin. J Fish Biol 72:1427-1449
Bricknell IR, Bron JE, Bowden TJ (2006) Diseases of gadoid fish in cultivation: a review. ICES J Mar Sci 63:253-266

Carroll ML, Cochrane S, Fieler R, Velvin R, White P (2003) Organic enrichment of sediments from salmon farming in Norway: environmental factors, management practices, and monitoring techniques. Aquaculture 226:165-180

$>$ Carss DN (1990) Concentrations of wild and escaped fishes immediately adjacent to fish farm cages. Aquaculture 90: $29-40$

Chambers CB, Ernst I (2005) Dispersal of the skin fluke Benedenia seriolae (Monogenea: Capsalidae) by tidal currents and implications for sea-cage farming of Seriola spp. Aquaculture 250:60-69

Chen H, Smith GJD, Zhang SY, Qin K and others (2005) Avian flu: H5N1 virus outbreak in migratory waterfowl. Nature 436:191-192

Christie KE, Graham DA, McLoughlin MF, Villoing S, Todd D, Knappskog D (2007) Experimental infection of Atlantic salmon Salmo salar pre-smolts by i.p. injection with new Irish and Norwegian salmonid alphavirus (SAV) isolates: a comparative study. Dis Aquat Org 75:13-22

Dagorn L, Josse E, Bach P, Bertrand A (2000) Modeling tuna behaviour near floating objects: from individuals to aggregations. Aquat Living Resour 13:203-211

deBruyn AMH, Trudel M, Eyding N, Harding J and others (2006) Ecosystemic effects of salmon farming increase mercury contamination in wild fish. Environ Sci Technol 40:3489-3493

Dempster T, Sanchez-Jerez P (2008) Coastal aquaculture and marine space planning in Europe: an ecological perspective. In: Holmer M, Black K, Duarte C, Marba N, Karakassis I (eds) Aquaculture in the ecosystem. Springer, Dordrecht, p 87-116

> Dempster T, Uglem I, Sanchez-Jerez P, Fernandez-Jover D, Bayle Sempere J, Nilsen R, Bjørn PA (2009) Coastal salmon farms attract large and persistent aggregations of wild fish: an ecosystem effect. Mar Ecol Prog Ser (in press)

> Ervik A, Kupka Hansen P, Aure J, Stigebrandt A, Johannessen P, Jahnsen T (1997) Regulating the local environmental impact of intensive marine fish farming. I. The concept of the MOM system (modelling-ongrowing fish farms-monitoring). Aquaculture 158:85-94

FAO (Food and Agricultural Organization) (2008) Fishstat plus. Aquaculture production: quantities 1950-2005. FAO, Rome

> Fernandez-Jover D, Lopez-Jimenez JA, Sanchez-Jerez P, Bayle-Sempere J, Gimenez-Casalduero F, MartinezLopez FJ, Dempster T (2007) Changes in body condition and fatty acid composition of wild Mediterranean horse mackerel (Trachurus mediterraneus Steindachner, 1868) associated to sea-cage fish farms. Mar Environ Res 63: $1-18$

Graham DA, Jewhurst H, McLoughlin MF, Sourd P, Rowley HM, Taylor C, Todd D (2006) Sub-clinical infection of farmed Atlantic salmon Salmo salar with salmonid alphavirus - a prospective longitudinal study. Dis Aquat Org 72:193-199

Hansen PK, Ervik A, Schaanning M, Johannessen P, Aure J, Jahnsen T, Stigebrandt A (2001) Regulating the local environmental impact of intensive, marine fish farming. II. The monitoring programme of the MOM system (modellingongrowing fish farms-monitoring). Aquaculture 194: 75-92

> Hastein T, Smith JE (1977) A study of Vibrio anguillarum from farmed and wild fish using principal components analysis. J Fish Biol 11:69-75

He P, Wardle CS (1988) Endurance at intermediate swimming 
speed of Atlantic mackerel, Scomber scombrus L., herring, Clupea harengus L., and saithe, Pollachius virens L. J Fish Biol 33:255-266

Heagney EC, Lynch TP, Babcock RC, Suthers IM (2007) Pelagic fish assemblages assessed using mid-water baited video: standardising fish counts using bait plume size. Mar Ecol Prog Ser 350:255-266

Jakobsen T (1978) Saithe tagging experiments on the Norwegian coast at $60^{\circ} 30^{\prime} \mathrm{N}$ in November-December 1974 . Fisken Havet 3:57-68

Krkosek M, Ford JS, Morton A, Lele S, Myers RA, Lewis MA (2007) Declining wild salmon populations in relation to parasites from farm salmon. Science 318:1772-1775

Nedreaas K (1987) Food and feeding habits of young saithe, Pollachius virens (L.), on the coast of western Norway. Fiskeridir Skr (Havunders) 18:263-301

Norwegian Fisheries Directorate (2008) Statistics for Aquaculture 2007. Available from: www.fiskeridir.no/fiskeridir/ kystsone_og_havbruk/statistikk

> Øines Ø, Simonsen JH, Knutsen JA, Heuch PA (2006) Host preference of adult Caligus elongatus Nordmann in the laboratory and its implications for Atlantic cod aquaculture. J Fish Dis 29:167-174

Sarno B, Glass CW, Smith GW (1994) Differences in diet and behaviour of sympatric saithe and pollack in a Scottish sea loch. J Fish Biol 45:1-11

Sepúlveda F, Marín SL, Carvajal J (2004) Metazoan parasites in wild fish and farmed salmon from aquaculture sites in southern Chile. Aquaculture 235:89-100

Skog TE, Hylland K, Torstensen BE, Berntssen MHG (2003)

Editorial responsibility: Hans Heinrich Janssen, Oldendorf/Luhe, Germany
Salmon farming affects the fatty acid composition and taste of wild saithe Pollachius virens L. Aquac Res 34:999-1007

Soto D, Jara F, Moreno C (2001) Escaped salmon in the Inner Seas, southern Chile: facing ecological and social conflicts. Ecol Appl 11:1750-1762

Stigebrandt A, Aure J, Ervik A, Hansen PK (2004) Regulating the local environmental impact of intensive marine fish farming. III. A model for estimation of the holding capacity in the modelling-ongrowing fish farm-monitoring system. Aquaculture 234:239-261

Sund O (1922) Marking of saithe in Norland (Norway), summer 1921. Report to the Director of Fisheries. Fiskeridir Skr 3:1-18

Thorstad EB, Fleming IA, McGinnity P, Soto D, Wennevik V, Whoriskey $F$ (2008) Incidence and impacts of escaped farmed Atlantic salmon Salmo salar in nature. In: Report from the Technical Working Group on Escapes of the Salmon Aquaculture Dialogue. NINA Spec Rep 36:1-112

Uglem I, Bjørn PA, Dale T, Kerwath S and others (2008) Movements and spatiotemporal distribution of escaped farmed and local wild Atlantic cod (Gadus morhua L.). Aquac Res 39:158-170

Underwood AJ (1997) Experiments in ecology: their logical design and interpretation using analysis of variance. Cambridge University Press, Cambridge

Wallace IS, Gregory A, Murray AG, Munro ES, Raynard RS (2008) Distribution of infectious pancreatic necrosis virus (IPNV) in wild marine fish from Scottish waters with respect to clinically infected aquaculture sites producing Atlantic salmon, Salmo salar L. J Fish Dis 31:177-186

Submitted: October 8, 2008; Accepted: March 9, 2009

Proofs received from author(s): May 19, 2009 